Centro de Estudios Constitucionales de Chile Universidad de Talca

"Los procedimientos de reforma en algunas Constituciones de América Latina.

Un estudio normativo con particular énfasis en la Constitución Ecuatoriana de 2008”

Jorge Benavides Ordóñez

\title{
LOS PROCEDIMIENTOS DE REFORMA EN ALGUNAS CONSTITUCIONES DE AMÉRICA LATINA. UN ESTUDIO NORMATIVO CON PARTICULAR ÉNFASIS EN LA CONSTITUCIÓN ECUATORIANA DE 2008*
}

\author{
THE AMENDMENT PROCEDURES IN SOME CONSTITUTION OF LATIN \\ AMERICA. A NORMATIVE STUDY WITH PARTICULAR EMPHASIS ON THE \\ ECUADORIAN CONSTITUTION OF 2008
}

\author{
Jorge BenaVides Ordóñez ${ }^{* *}$ \\ Universidad de las Américas \\ jorge.benavides@udla.edu.ec
}

RESUMEN: En el manuscrito se persigue analizar los distintos procedimientos de reforma en varias Constituciones de América Latina, ya sea por la importancia que suponen algunas de ellas para el constitucionalismo en la región, o por la novedad que algunas de aquellas revisten, en términos de derechos, así como en cuestiones de organización institucional. Dicho análisis de carácter, primordialmente normativo, tiene como objetivo final el determinar el nivel de desarrollo en materia de reforma constitucional que supone el diseño constitucional ecuatoriano.

ABSTRACT: In the manuscript is intented to analyze the ways of amendment in several constitution of Latin America, either by the importance that they pose some of them to the Constitutionalism in the region, or by the news that some of those are, in terms of rights and issues of institutional organization. Said analysis of character, primarily, normative has as objective end the determine the level of development in matters of amendment constitutional that assumes the design constitutional Ecuadorian.

PALABRAS CLAVES: Reforma constitucional; Rigidez constitucional; Referéndum; Asamblea Constituyente; América Latina.

KEYWORDS: Amendment constitution; Constitutional rigid; Referéndum; Constituent Assembly; Latin America.

\footnotetext{
* Artículo recibido el 27 de marzo de 2017 y aprobado el 25 de abril de 2018.

** Abogado, P. Universidad Católica de Ecuador, máster y doctor en Derecho Constitucional, Universidad de Sevilla. Profesor a tiempo completo en la Universidad de las Américas, Quito, y profesor contratado de la Universidad Andina Simón Bolívar, sede Ecuador.
} 


\section{INTRODUCCIÓN}

La reforma constitucional se trata, pues, de un tema, más o menos recurrente en las últimas décadas en América Latina, sobre todo en algunos países identificados como parte del movimiento conocido como nuevo constitucionalismo latinoamericano ${ }^{1}$. En efecto, algunos señalan a la Constitución brasileña de 1988 como el origen de dicho movimiento, texto constitucional que fue seguido por la Constitución colombiana de 1991, apareciendo, posteriormente, la Constitución venezolana de 1999; luego surgió la Constitución ecuatoriana de 2008 y, finalmente, la Constitución boliviana de $2009^{2}$. Si bien, los casos mencionados aluden a la adopción de nuevos Textos constitucionales, hubo importantes reformas a otras Constituciones con una larga vigencia y tradición en la región como la efectuada a la Constitución argentina en 1994, o las cientos de reformas sufridas, a lo largo del tiempo, por la Constitución mexicana de 1917, o las reformas introducidas a la Constitución costarricense de 1949. Lo cierto es que, en los últimos tiempos, ha recobrado fuerza la discusión respecto a la reforma constitucional en Chile, en Colombia, e incluso en Ecuador, que de los tres países exhibe el Texto constitucional más joven, y que, a pesar de ello, ha sido modificado en aspectos esenciales por tres ocasiones (2011, 2015 y 2018).

En este sentido, el presente trabajo pretende analizar los distintos procedimientos de reforma en varias Constituciones de América Latina, ya sea por la importancia que suponen algunas de ellas para el constitucionalismo en la región, o por la novedad que algunas de aquellas revisten, en términos de derechos, así como en cuestiones de organización institucional. Dicho análisis de carácter, primordialmente normativo, tiene como objetivo final el determinar el nivel de desarrollo en materia de reforma constitucional que supone el diseño constitucional ecuatoriano.

En consecuencia, en las líneas que siguen se partirá determinando las funciones de la institución de la reforma constitucional. Posteriormente, se describirá la regulación de los procedimientos de la reforma en Ecuador, para luego realizar un ejercicio comparado de dichos procedimientos con otros Textos de América Latina en temas como la iniciativa; el trámite, el cual, a su vez, incluye aspectos como las mayorías requeridas para la aprobación del proyecto de reforma, el nú-

1 Entre la amplia literatura al respecto destaca el texto de PisArello, Gerardo (2012): Procesos constituyentes. Caminos para la ruptura democrática (Madrid, Editorial Trotta).

2 Viciano Pastor y Martínez Dalmau (2010), pp. 18 y ss. 
mero de discusiones del proyecto, la existencia o no, por un lado del referéndum y, por otro, de Asambleas Constituyentes y Constitucionales. Luego de lo cual estaremos en condiciones de hacer una valoración de los distintos procedimientos de reforma de los Textos constitucionales analizados, con especial hincapié en el caso ecuatoriano.

\section{LA REFORMA CONSTITUCIONAL Y SUS FUNCIONES}

Como es bien conocido, los actuales Estados constitucionales se caracterizan en gran medida por la existencia de Constituciones rígidas ${ }^{3}$, así como por el establecimiento de la justicia constitucional. Ciertamente, tanto la reforma de Textos constitucionales rígidos como la justicia constitucional, se trata de dos importantes garantías de la Constitución. Sin embargo, se debe tener presente que transitan en vías distintas, de ahí que la justicia constitucional se integra de modo cotidiano a la vida en comunidad, asegurando la adecuación de la interpretación constitucional a las cambiantes circunstancias sociales dentro del marco de posibilidades interpretativas permitidas por el Texto constitucional. Lo dicho supone, como advierte Pérez Royo, que aquella justicia opera como una garantía ordinaria de la Constitución, en tanto que la reforma constitucional actuaría como una garantía extraordinaria. En la medida en que a ella solo se debe acudir cuando no es posible encontrar respuesta a un problema a través de la interpretación ${ }^{4}$. O, lo que es lo mismo, la problemática de la reforma constitucional empieza donde terminan las posibilidades de la mutación de la Constitución 5 .

Un dato que llama poderosamente la atención respecto de la reforma, como garantía extraordinaria de la Constitución, es el hecho de que en aquella conviven dos funciones claramente diferenciadas entre sí. A decir de Garrorena, el procedimiento de reforma constitucional supone una tesis bifronte, en la medida en

\footnotetext{
$3 \mathrm{Al}$ punto que, a decir de De VEGA, se trata de una regla universal que encontraría una excepción en el constitucionalismo inglés o en el constitucionalismo neozelandés. De VEGA (1985), p. 50. Versiones de constitucionalismo que, como anota BAYÓN, se diferenciarían de un constitucionalismo en un sentido más restringido, a la usanza, por ejemplo, del modelo estadounidense, así como del europeo Kelseniano, lo cuales abrazarían como premisas, sobre todo el segundo modelo, la limitación material del poder normativo del legislador, aupado por la existencia de constituciones rígidas y de tribunales constitucionales. BAYÓN (2010), pp. 411-413.

4 Pérez Royo (2007), p. 150.

5 Hesse (1992), p. 24.
} 
que se acude a dicho procedimiento con el fin de estabilizar la Constitución por un lado, y a hacer posible su modificación, por otro ${ }^{6}$.

Ciertamente, la finalidad dual del procedimiento de reforma explicita dos de sus principales funciones, a saber, la búsqueda de la permanencia de la Constitución, en el sentido de que puede ser modificada, si, y solo si, se sigue un procedimiento agravado distinto del previsto para las leyes. En otras palabras, la estabilidad viene dada por el hecho de que al tratarse de un Texto rígido las mayorías políticas circunstanciales no pueden cambiarlo con las mismas facilidades como sucede con cualquier texto legal. Por otro lado, la existencia misma de cláusulas de reforma en las Constituciones supone la posibilidad de proceder a un cambio ordenado y debidamente regulado, cuando las posibilidades de interpretación constitucional no sean suficientes de cara a un problema presentado en la comunidad en donde la Constitución rige.

Se debe tener presente que la tensión entre el cambio y la permanencia, o binomio movilidad-rigidez planteado por $\mathrm{Hesse}^{7}$, que subyace a la reforma constitucional es, en definitiva, una disputa difícil de saldarla en términos absolutos y, que, por tanto, encuentra una solución relativa en términos de mayor rigidez o mayor flexibilidad ${ }^{8}$. De ahí que en el mismo sentido De Vega sostiene que en los tiempos que corren, en lugar de hablar de textos constitucionales rígidos o flexibles, a partir de la clasificación realizada tempranamente por Bryce, se debería hablar de constituciones con mayor o menor grado de rigidez ${ }^{9}$.

Desde una arista democrática, por otra parte, la reforma constitucional tendría como función, la tarea de arreglar desaciertos que el Texto constitucional pudiera contener. En esa medida, es que el constituyente consciente de su falibilidad decide por medio de la reforma la apertura de la Constitución hacia las decisiones de las mayorías políticas futuras ${ }^{10}$. En cualquier caso, el ejercicio del poder de reforma por parte de las mayorías, o mejor dicho mayorías calificadas si nos ubicamos ante Constituciones rígidas, deberá enmarcarse dentro de los límites impuestos por el ordenamiento jurídico, respetando, en consecuencia, los límites tanto materiales,

${ }^{6}$ Garrorena (2014), p. 99.

7 Hesse (1992), pp. 23 y ss.

8 Garrorena (2014), p. 100.

9 De Vega (1985), p. 50.

10 Ferreres Comella (2012), pp. 212-213. 
así como procedimentales impuestos por el constituyente originario ${ }^{11}$. Premisa de actuación que, en suma, debería ser abrazada por parte de los poderes constituidos de cualquier Estado constitucional.

\section{El procedimiento de REFORMA CONSTITUCIONAL EN ECUADOR}

La Constitución ecuatoriana de 2008 regula su reforma en los artículos 441, 442 y 444. Así, el primero de ellos desarrolla la denominada enmienda constitucional; el segundo, por su parte, describe el proceso de reforma constitucional y; el último, se refiere al cambio de elementos esenciales de la Constitución, que puede ser llevado a cabo solo por Asamblea Constituyente, convocada por consulta popular, ya sea, a petición del pueblo, de la Asamblea Nacional o del presidente de la República. El orden señalado por el Texto constitucional va del menos al más rígido de los procedimientos, lo cual va vinculado a los temas que pueden ser modificados por cada uno de ellos. En consecuencia, la enmienda al ser el mecanismo menos rígido tiene como límites los elementos constitutivos del Estado, la estructura fundamental de la Constitución, el cambiar el procedimiento de reforma y el restringir los derechos constitucionales. La reforma parcial, por su lado, al tratarse de un procedimiento que supone un mayor grado de rigidez, tiene como límites exclusivamente el cambiar el procedimiento de reforma y el restringir los derechos constitucionales. Finalmente, la Asamblea Constituyente, el trámite más agravado de los tres, está prevista para cambiar el procedimiento de reforma, así como en caso de una modificación restrictiva de los derechos constitucionales, Asamblea que solo puede nacer por consulta popular.

Respecto a los límites formales a la reforma constitucional destacan la exigencia de dos tercios en el Parlamento, así como la exigencia de doble deliberación parlamentaria, mediando un año entre el primer y segundo debate en el caso de la enmienda, y de 90 días entre el primero y el segundo en caso de la reforma parcial. En cuanto a los límites materiales, el artículo 84, así como los artículos 441 y 442 de la Constitución operan como cláusulas de intangibilidad, al prescribir, entre otras cosas, que la reforma de la Constitución no podrá restringir el alcance de los derechos.

11 Como advierte Bockenforde, incluso en el ejercicio del poder constituyente originario no hay cabida para un uso arbitrario de dicho poder, en la medida en que al tener el poder constituyente originario como fin la creación de la Constitución, esta supone, ulteriormente, la organización jurídica y racional del poder estatal. BOCKENFORDE (2000), p. 176. 
Para comprender adecuadamente los procedimientos de reforma constitucional es necesario, en definitiva, conocer a grandes líneas el modelo en donde aquella se inserta. En tal sentido, el artículo $1^{\circ}$ de la Constitución define a Ecuador como un Estado constitucional de derechos y justicia, en donde la soberanía radica en el pueblo y se ejerce por medio de los órganos del poder público y por las formas de participación directa previstas en la Constitución. De dicho artículo, consecuentemente, podemos colegir dos de los elementos característicos de la Constitución ecuatoriana, por un lado, el garantismo ${ }^{12} \mathrm{y}$, por otro, el participativo ${ }^{13}$. La interacción de ambos elementos da como resultado la rigidez selectiva del Texto ecuatoriano, el cual, entre otras cosas, supone que a mayor calado de la reforma, mayor será el nivel de participación ciudadana para que se produzca el cambio.

Ciertamente, la idea que subyace a la intervención directa del poder constituyente del pueblo, cuando se intente cambiar aspectos de la Constitución material, tendría como antecedente la distinción formulada por Schmitt entre Constitución y ley constitucional. Así, los derechos y los procedimientos que regulan la reforma al Texto constitucional serían parte de la decisión política fundamental del titular del poder constituyente ${ }^{14}$.

\section{LOS PROCEDIMIENTOS DE REFORMA EN ALGUNOS teXtos CONSTITUCionales de AmÉrica Latina}

En el presente acápite examinaremos en perspectiva comparada los procedimientos de reforma de los Textos constitucionales de Argentina, Bolivia, Brasil, Chile, Colombia, Costa Rica, Ecuador, México, Perú y Venezuela. Nos hemos decantado por estos Textos, en la medida en que se trata de Constituciones

12 En el sentido de que la Constitución ecuatoriana posee un extenso catálogo de derechos, entre los que destaca el sumak kawsay o buen vivir, el cual recogiendo la herencia ancestral indígena, promueve la relación armoniosa del individuo con la naturaleza. De otro lado, se recoge también un profuso grupo de garantías constitucionales.

13 Por la importancia que otorga la Constitución ecuatoriana a los instrumentos de democracia directa en sus distintas modalidades, tales como la iniciativa popular tanto legislativa como constitucional, la consulta popular en sus modalidades de referéndum y plebiscito, el primero de los cuales tiene el objeto de introducir textos normativos concretos, por ejemplo, a la Constitución, en tanto que el segundo mecanismo está previsto para consultas de carácter social, político o económico, que para su posterior eficacia, de precisar alguna reforma normativa, será el órgano correspondiente el encargado de hacer efectivo el pronunciamiento ciudadano. Además, el texto constitucional contempla la revocatoria del mandato a todo funcionario de elección popular.

14 Sснмітт (2012), p. 60. 
particularmente importantes en el ámbito latinoamericano por su significación histórica o por aportar novedades al panorama del constitucionalismo de la región. Debemos señalar que el análisis será normativo, en sede constitucional. Así, empezaremos con la iniciativa, para luego referirnos al trámite de aprobación, etapa que incluye el estudio de la mayoría requerida para la aprobación, así como el número de debates parlamentarios, pasando; posteriormente, a revisar cuáles de los textos constitucionales analizados contemplan la figura del referéndum, por un lado, y los que incorporan la figura de la Asamblea Constituyente, por otro.

\subsection{Iniciativa}

Las Constituciones analizadas, en términos generales, confieren la iniciativa de reforma constitucional al Ejecutivo, al Legislativo y a la ciudadanía. De ahí que los Textos de Colombia (art. 375), Ecuador (arts. 441-442), México ${ }^{15}$, Perú (art. 206) y Venezuela (arts. 341-432) otorguen por igual la potestad de presentar iniciativas de reforma al Presidente de la República, al Congreso Nacional y a los ciudadanos.

De otro lado, están aquellos Textos constitucionales que confieren iniciativa solamente al Ejecutivo y a los parlamentarios, esto es, en uso de la potestad constituyente derivada. Tal es el caso de Brasil (art. 60) y Chile (art. 116). Entre tanto, las Constituciones de Bolivia (art. 441 II) y Costa Rica (art. 195 I) confieren la iniciativa para reforma parcial de la Constitución a la Legislatura y a la ciudadanía. Finalmente, nos encontramos con la Constitución de Argentina, la cual prescribe que la necesidad de reforma constitucional debe ser declarada por el propio Congreso, con el voto favorable de dos tercios de sus miembros (art. 30).

Resalta, en consecuencia, el papel de la iniciativa ciudadana para reformar la Constitución. En efecto, el hecho de que las Constituciones de Bolivia, Colombia, Costa Rica, Ecuador, Perú y Venezuela la contemplen da muestra de la importancia que otorgaron los respectivos constituyentes a la participación de la voluntad popular cuando de modificaciones al Texto constitucional se trata ${ }^{16}$.

15 El artículo 135 de la Constitución de México no dice nada respecto de la iniciativa. Sin embargo, en la práctica la iniciativa corresponde a aquellos que tienen facultad para presentar proyectos de ley. Así, de conformidad al artículo 71 del Texto constitucional mexicano, la iniciativa corresponde al Presidente de la República, al Congreso de la Unión, a las Legislaturas de los Estados y a los ciudadanos en un porcentaje equivalente al 0.13 del registro electoral.

16 La impronta participativa de la ciudadanía en la construcción de la voluntad pública, es decisiva a la hora de regular los mecanismos de reforma constitucional, por ejemplo, en las Constituciones de Colombia, 
El caso de México supone una singularidad, en la medida en que, ante el silencio del constituyente sobre la iniciativa de reforma constitucional, la práctica constitucional ha considerado que dicha facultad la poseen todos aquellos que pueden presentar proyectos de ley (art. 71). Por el contrario, las Constituciones de Argentina, Brasil, Chile, tienen en común el no contemplar la iniciativa popular para la reforma de la Constitución.

Por tanto, daría la impresión de que la distinción de dar o no cabida a la iniciativa ciudadana para la reforma constitucional, obedece a si estamos frente a textos constitucionales de nuevo cuño ${ }^{17}$, los cuales en su mayoría la contemplan, con excepción de la Constitución de Brasil de 1988. O, si estamos hablando de Textos constitucionales de corte clásico, entre las que suponen excepciones, por un lado, la Constitución de Costa Rica de 1949, en la medida en que prevé expresamente la iniciativa ciudadana para su revisión parcial, y, por otro, la Constitución de México de 1917, con la particular interpretación que lleva a conferir iniciativa de reforma constitucional a los mismos órganos facultados para la iniciativa legislativa ordinaria.

Es necesario, sin embargo, señalar que los Textos constitucionales que contemplan la iniciativa ciudadana para la reforma lo hacen exigiendo distintos porcentajes de participación, que van del veinte por ciento del registro electoral exigido en Bolivia (art. $411 \mathrm{II}$ ), al quince por ciento solicitado en Venezuela tanto para la enmienda como para la revisión parcial (arts. 341 y 342, respectivamente), o al cinco por ciento pedido en Colombia (art. 375) y Costa Rica (art. 195 I), hasta llegar al cero punto tres de Perú (art. 206) y al exiguo cero punto trece de México (art. 71 IV). En este marco, Ecuador se inscribe dentro de los países que exigen porcentajes medios, con el ocho por ciento de las personas inscritas en el registro electoral para la enmienda y el uno por ciento para la reforma (arts. 441 y 442, respectivamente).

De otro lado, en relación con la facultad de iniciativa de reforma cuando esta corresponde a los miembros del Poder Legislativo conformado por dos Cámaras, aquella incluye, normalmente, a los integrantes del Congreso y del Senado, como es el caso de la Constitución de Brasil (art. 60 I), de la Constitución de México (art.

Venezuela, Ecuador y Bolivia, en materias como el establecimiento de la iniciativa ciudadana, la previsión de referéndum y de Asambleas Constituyentes. Al respecto véase, Benavides Ordóñez (2016), p. 184.

17 Los nuevos textos constitucionales latinoamericanos no pueden ser clasificados como uniformes. Existen, sin embargo, aspectos en los que confluyen, como la importancia de los derechos y garantías, así como el papel que juegan los tribunales en su realización. Al respecto véase, UprimnY (2011), pp. 128 y ss. Por su lado, Gargarella, a su vez, considera como auténticamente innovadores las Constituciones de Ecuador y Bolivia, las que, a pesar de sus grandes imperfecciones, dice el profesor argentino, representan un interesante intento de innovación institucional. Gargarella (2011), nota al pie 2. 
71 II), de la Constitución de Chile (art. 116) y de la Constitución de Colombia (art. 375). La Constitución argentina, por su parte, en su artículo 30 confiere la facultad de declarar la necesidad de reforma constitucional al Congreso.

Un elemento importante de los procedimientos de reforma es el del apoyo requerido entre los miembros de la Asamblea legislativa para la presentación de una iniciativa de reforma constitucional en sede parlamentaria. La exigencia de porcentajes amplios de apoyo revela la intención, no solo de dar rigidez a la Constitución, sino también de obstaculizar el propio debate sobre la posibilidad o conveniencia de reformar la Constitución.

Respecto a este elemento, podemos distinguir las Constituciones de Brasil y Venezuela, que exigen requisitos elevados para la iniciativa parlamentaria de reforma. Así, en el primero de dichos países la iniciativa debe ir apoyada por un tercio de los miembros del Congreso o del Senado, así como la mayoría de los miembros de las Asambleas Legislativas de la Federación (arts. 60 I y III), mientras que en el segundo la iniciativa para la enmienda se reserva al treinta por ciento, como mínimo, de los miembros de la Asamblea Nacional (art. 341), en tanto que respecto a la reforma parcial se requiere que la iniciativa venga apoyada, al menos, por la mayoría de los miembros de dicho órgano (art. 342).

Constituciones con requisitos menos exigentes son la de Colombia, que prescribe que un proyecto de acto legislativo de reforma constitucional puede ser iniciado por diez miembros del Congreso o por el veinte por ciento de los diputados (art. 375) y la de Costa Rica, que establece que la iniciativa de proposición de reforma parcial deberá ser firmada por diez diputados (art. 195), si bien esta última Constitución prevé que las proposiciones de reforma pasen por un complicado sistema de lecturas y votaciones que exige, entre otros elementos, que la procedencia de la reforma sea declarada por votación de no menos de los dos tercios del total de los miembros de la Asamblea. Esta última Constitución presenta, de hecho, un interesante equilibrio, ya que marca la iniciativa de reforma con la impronta de la rigidez constitucional pero, al mismo tiempo, permite la discusión de la iniciativa, si bien logra dicho equilibrio a costa de una notoria complejidad procedimental. Finalmente, un caso extremo es el de la Constitución de Chile, la cual prescribe que la iniciativa para presentar un proyecto de reforma constitucional le corresponde a cualquiera de los miembros del Congreso (art. $116)^{18}$.

18 Respecto al procedimiento de reforma constitucional en Chile, véase Nogueira Alcalá (2009). 
Por otra parte, existen Constituciones en las que la iniciativa se confiere a los parlamentarios de forma genérica, sin concretar ningún porcentaje, como es el caso de la de México, que atribuye la iniciativa legislativa, que engloba la de reforma constitucional, a los diputados y senadores del Congreso de la Unión y a los miembros de las Asambleas Federales (arts. 71 II y III), la de Perú, que señala, simplemente, que dicha facultad corresponde a los congresistas (art. 206), y la de Bolivia, que atribuye la iniciativa a las dos terceras partes de los miembros de la Asamblea Legislativa Plurinacional, pero refiriendo esta mayoría a la aprobación parlamentaria de la reforma, entendida como iniciativa de reforma en el marco de un procedimiento que incluye como último y necesario paso la aprobación en referéndum. Caso singular es el de la Constitución de Argentina, que no concreta el porcentaje de apoyo que debe llevar la iniciativa de reforma, pero exige una mayoría de dos tercios de los miembros del Congreso para declarar su necesidad, lo cual va seguido de la convocatoria de una Convención (art. 30). En estos países, por tanto, la regulación concreta de la iniciativa parlamentaria de reforma parece encomendada a los correspondientes reglamentos legislativos.

La regulación de este tema en Ecuador coincide con la de Venezuela, puesto que la Constitución ecuatoriana exige en su artículo 341 que la iniciativa para la enmienda sea respaldada por el treinta por ciento de los miembros de la Asamblea Nacional, en tanto que la iniciativa para la reforma parcial debe ser respaldada por la mayoría de los miembros de dicho órgano (art. 342). Por lo tanto, se encuentra la Constitución de Ecuador entre las que exigen el mayor porcentaje de apoyo legislativo para el ejercicio de la facultad de presentar una iniciativa encaminada a modificar su articulado, el cual, además, se agrava cuando la materia afectada quede reservada al procedimiento de reforma constitucional.

Los Congresos Nacionales bicamerales, por lo general, suelen estar vinculados a la forma federal de Estado ${ }^{19}$, en la medida en que el Congreso es la Cámara que representa a los ciudadanos y el Senado a los territorios, como ocurre en el caso de Argentina, Brasil y México. De estos, los dos últimos países citados confieren la iniciativa de reforma también a las asambleas de los entes federados. La particularidad en este apartado viene representada por Venezuela, donde, a pesar de tratarse de un Estado federal, el Poder Legislativo se organiza según el modelo unicameral (art. 186).

19 Sin embargo, de las Constituciones estudiadas, tanto la de Colombia (arts. $1^{\mathrm{o}}$ y 132 ) como la de Chile (arts. $3^{\circ}$ y 46) prescriben que se tratan de Estados unitarios que cuentan con Congresos bicamerales. 
Por otra parte, la Constitución de Colombia presenta la singularidad de atribuir la facultad de presentar una iniciativa de reforma constitucional a los concejales municipales y a los diputados departamentales (art. 375), en la medida en que dicha atribución supone la participación de los entes territoriales menores, municipios y departamentos, por medio de la posibilidad de que el veinte por ciento de los concejales y diputados que integran los municipios y asambleas departamentales presenten proyectos de revisión constitucional, si bien la Corte Constitucional ha limitado esta facultad al presupuesto de que los proyectos se refieran a cuestiones atinentes al nivel de gobierno local ${ }^{20}$.

\subsection{Trámite}

El análisis se hará, principalmente, a partir de la mayoría legislativa requerida para la aprobación de la reforma constitucional. Adicionalmente se estudiará otro elemento complementario del procedimiento de reforma que, si se da, comporta un mayor grado de rigidez, como es el requisito de la necesidad de dos debates, es decir, un modelo de doble discusión parlamentaria, frente al modelo de una sola discusión parlamentaria.

\section{a) Mayoría requerida para la aprobación}

La mayoría prevista más frecuentemente para la aprobación de la reforma constitucional por parte de las correspondientes Cámaras legislativas es de dos tercios. En este modelo se inscriben las Constituciones de Bolivia (art. 411 II), Chile (art. 116), Costa Rica (art. 195 VII), Ecuador (arts. 441-442), Venezuela (art. 342) y México (art. 135), si bien, en el caso de Chile, dicha exigencia se da cuando se quiere reformar determinadas materias relacionadas con las bases institucionales o con los derechos, en tanto que si la reforma no se refiere a dichas materias, la Constitución exige una mayoría calificada de tres quintos, y en el caso

\footnotetext{
$20 \mathrm{Al}$ respecto existe una contradicción entre los artículos 375 y el 155 de la Constitución de Colombia, en la medida en que el primero señala el veinte por ciento de los concejales y diputados, en tanto que el segundo habla del treinta por ciento. RAMírez Cleves aclara el tema al señalar que la Corte Constitucional de Colombia, en sus sentencias, acoge el criterio del treinta por ciento de los concejales o de los diputados. Además, el autor señala que, a decir de la Corte, no procede la iniciativa por combinación de concejales y diputados, y, lo más importante, que los proyectos presentados por los entes territoriales, municipios y departamentos deben referirse exclusivamente a temas relacionados con sus intereses y necesidades. Véase, Ramírez Cleves (2005), p. 448, nota al pie 26.
} 
de Venezuela, quedan exceptuados los cambios constitucionales susceptibles de ser tramitados por el procedimiento de enmienda, que requiere sólo la mayoría de los integrantes de la Asamblea Nacional. Por otra parte, en el caso de la Constitución de México se debe advertir que se exigen dos tercios de los presentes en la sesión y no de la totalidad de los miembros del Congreso y, además, la mayoría de las Legislaturas de los Estados de la Federación.

En Chile, si la reforma no afecta a las materias anteriormente señaladas, y Brasil la mayoría parlamentaria exigida es de tres quintos (art. $60 \mathrm{II}$ ). Por último, las Constituciones de Colombia, Perú (art. 206) y Venezuela (art. 341) contemplan la mayoría absoluta para proceder a su reforma. Sin embargo, en Colombia, si la reforma comprometiera a los derechos y sus garantías, a la participación democrática o al Congreso, podría ser sometida a referéndum si fuera solicitada dentro de los seis meses posteriores a su promulgación, siempre y cuando la petición contara con el respaldo de, al menos, el cinco por ciento de los ciudadanos inscritos en el registro electoral (art. 377). Finalmente, en Venezuela se requiere para la enmienda el voto de la mayoría de los integrantes de la Asamblea Nacional, lo que la distingue del procedimiento de reforma constitucional, que exige mayoría de las dos terceras partes de los miembros de aquélla.

\section{b) El número de discusiones parlamentarias}

El modelo habitual es el de doble discusión parlamentaria, que obliga a que la reforma constitucional sea aprobada por la Asamblea parlamentaria en dos deliberaciones sucesivas, mediando entre ellas un cierto espacio de tiempo. La doble deliberación legislativa es contemplada en Brasil, Colombia, Costa Rica, Ecuador, Perú y Venezuela, si bien debe señalarse, para el caso de Ecuador, que esto no supone una singularidad sobre el procedimiento legislativo ordinario,

que también requiere dos lecturas. Dicha aprobación parlamentaria, en algunos casos, es definitiva, esto es, no precisa referéndum, como ocurre en las Constituciones de Brasil (art. 60), de Ecuador, en el caso de la enmienda de iniciativa de la Legislatura (art. 441), y de Perú, donde, como alternativa al referéndum, se exige la doble deliberación parlamentaria (art. 206).

El caso más extremo de complejidad en el procedimiento de reforma es el de la Constitución de Costa Rica, en el que la iniciativa de reforma debe pasar por múltiples lecturas, votaciones y reelaboraciones, tanto en la fase de admi- 
sión, como en la de tramitación y en la de aprobación. De entrada, la iniciativa de reforma debe ser sometida a tres lecturas en la Asamblea, mediando seis días de separación entre cada una, para determinar si se admite o no la propuesta a discusión. Posteriormente, de ser admitida la propuesta, pasa a una comisión nombrada por mayoría absoluta de la Asamblea, la cual tendrá que dictaminar en un término de veinte días. Una vez presentado el dictamen por parte de la comisión de la Asamblea se procederá a discutirlo siguiendo el trámite legislativo ordinario. La reforma, para su aprobación, precisa de, al menos, los dos tercios de los miembros de la Asamblea, pero cabe aclarar que esta aprobación sirve tan sólo para determinar la procedencia de la reforma. A partir de este momento empieza el trámite de aprobación de la reforma y, con este fin, la Asamblea, nuevamente por medio de una comisión, prepara el respectivo proyecto de reforma constitucional, el cual requiere para su aprobación la mayoría absoluta de los integrantes del legislativo. Una vez que el proyecto ha sido aprobado, debe ser remitido al Ejecutivo, el cual, a su vez, lo devolverá a la Asamblea al inicio de la siguiente legislatura ordinaria, haciéndole conocer, en caso de existir, sus observaciones. A partir de ahí, la Asamblea Legislativa, en sus primeras sesiones, tiene la obligación de discutir el proyecto en tres debates, debiendo aprobarlo definitivamente con la anuencia de los dos tercios de sus miembros, con posibilidad de referéndum si así lo acuerda también la mayoría de dos tercios de dicho órgano (art. 195). La de Costa Rica, por tanto, es una Constitución en la que el grado de rigidez, a decir verdad muy extremo, se consigue no solo mediante la previsión de una elevada mayoría para la aprobación de la reforma, sino también mediante la acumulación de un número muy alto de debates, votaciones y trámites intermedios.

Con respecto a Venezuela, la iniciativa de reforma constitucional será tramitada por la Asamblea Nacional del siguiente modo: una primera lectura en el período de sesiones correspondiente a la presentación del mismo, una segunda lectura por Título o Capítulo, dependiendo del caso, y una tercera y última lectura artículo por artículo. La Asamblea Nacional deberá aprobar el proyecto de reforma constitucional en un plazo que no supere los dos años a partir de la fecha en que conoció y aprobó el proyecto, contando para ello, con la voluntad de los dos tercios de los miembros de dicho órgano (art. 343). Luego de la aprobación de la reforma constitucional por parte de la Asamblea Nacional esta debe ser sometida a referéndum dentro de los treinta días posteriores a su sanción (art. 344).

Por el contrario, en el modelo de una sola deliberación parlamentaria para la reforma parcial de la Constitución se encuentran Chile (art. 117) y Bolivia (art. 441 II). Sin embargo, existe una diferencia importante entre estas dos Constituciones, la 
cual consiste en que cualquier modificación al Texto constitucional boliviano debe ser puesta a consideración final del electorado, a través de referéndum, mientras que en Chile el referéndum solo se prevé, a modo de plebiscito, como recurso del Presidente en caso de desacuerdo con una reforma constitucional aprobada por el Congreso por mayoría de dos tercios de sus miembros.

En definitiva, en el trámite de reforma parcial a la Constitución, el número de debates parlamentarios requerido y la existencia o no de referéndum ratificatorio son elementos importantes, en la medida en que, por un lado, permiten establecer el grado de rigidez de una Constitución, y, por otro, permiten medir la importancia que el procedimiento de reforma da a la deliberación en sede legislativa y a la participación popular.

$\mathrm{Al}$ evaluar los diferentes grados de rigidez de los procedimientos de reforma, debe distinguirse entre las Constituciones que recogen un único procedimiento de reforma y aquellas que prevén requisitos especialmente agravados para la reforma de la regulación de materias a las que la Constitución ha querido dar especial importancia.

En el grupo de las Constituciones que recogen solo un procedimiento de reforma se encuentran las de Argentina, Brasil y México. Por su parte, la Constitución de Perú supone un caso especial, ya que recoge dos procedimientos, dependiendo de las mayorías parlamentarias que aprueben la reforma y de que se llame o no a referéndum, pero extiende ambos procedimientos a la modificación de cualquier artículo de la Constitución (art. 206).

En el grupo de las Constituciones que exigen requisitos especiales para la reforma de los artículos que regulan determinadas materias se incluyen las de Bolivia, Chile, Colombia, Costa Rica, Venezuela y Ecuador.

Las materias a las que afectan los requisitos especiales suelen coincidir con los principios y las estructuras políticas fundamentales del Estado y los derechos reconocidos por la Constitución. En particular, la Constitución de Ecuador se adscribe al grupo de las que contemplan requisitos especiales para la modificación de la regulación constitucional de determinadas materias. Así, como hemos visto, el cambio que afecte a la estructura fundamental de la Constitución o al carácter y los elementos constitutivos del Estado, debe ser tramitado a través del procedimiento de reforma parcial, que exige aprobación parlamentaria y referéndum de manera necesaria y consecutiva, al contrario de lo que ocurre con el procedimiento de enmienda, en el que la tramitación parlamentaria y el referéndum se configuran como vías alternativas. Los procedimientos de enmienda y de reforma incluyen 
también algunas diferencias en la regulación, tanto de la iniciativa parlamentaria, como de la iniciativa de origen ciudadano, tal como hemos visto anteriormente.

Asimismo, la Constitución de Ecuador exige la convocatoria de Asamblea Constituyente para los cambios que afecten a los derechos reconocidos en la Constitución y al proceso de reforma, en cuyo caso la reforma constitucional queda homologada a la aprobación de una nueva Constitución. En esa medida, la Constitución de Ecuador se encuadra dentro de las que escalonan la rigidez de los procedimientos de reforma conforme a la importancia de las materias afectadas.

\section{c) Previsión de referéndum}

De las Constituciones estudiadas, contemplan el referéndum constitucional las de Bolivia (art. $411 \mathrm{II}$ ), Chile (art. 117), Colombia (art. 375), Costa Rica (art.195 VIII) Ecuador (arts. 441 y 442), Perú (art. 206) y Venezuela (arts. 341 y 342). De estos Textos, a su vez, los de Bolivia y Ecuador contemplan expresamente y de forma diferenciada también el referéndum constituyente, el cual tiene como finalidad aprobar una nueva Constitución y no solo el aprobar una revisión parcial de esta, como ocurre con el referéndum constitucional. El referéndum constituyente se desprende de la previsión de Asamblea Constituyente prescrita en las Constituciones de Ecuador y Bolivia, ya que la nueva Constitución aprobada por la Asamblea debe ser ratificada en ambos países por referéndum ${ }^{21}$.

En Ecuador, cuando la enmienda, procedimiento menos rígido para reformar la Constitución, es de iniciativa de la Legislatura, se prescinde del referéndum constitucional, mientras que en Venezuela se exige el referéndum constitucional, ya se trate de enmienda o de reforma parcial. En Bolivia, por su parte, no existe el procedimiento de enmienda, sino tan solo el de reforma parcial de la Constitución, la cual debe ser ratificada por referéndum constitucional.

Por su lado, Chile, Perú, Colombia, Costa Rica y Venezuela acogen exclusivamente el referéndum constitucional. Así, el artículo 117 de la Constitución chilena contempla el plebiscito bajo dos condiciones. La primera, cuando el Presidente de la República objetara totalmente un proyecto de reforma constitucional aprobado por la mayoría absoluta de los miembros del Congreso, y éste insistiese en la totalidad del proyecto por medio de las dos terceras partes de los miembros de las dos Cámaras, y la segunda cuando existiese la objeción parcial por parte

${ }^{21}$ Colombia y Venezuela también contemplan en sus Constituciones Asambleas Constituyentes. Sin embargo, en aquellas no se prevé referéndum constituyente para que entre en vigor la nueva Constitución. 
del Presidente de la República a un proyecto de reforma constitucional aprobado por el Congreso. En tal caso, si el último se ratifica en el proyecto inicial por una mayoría de dos terceras partes, el Presidente, en vez de promulgarlo, puede consultar a la ciudadanía por medio de plebiscito ${ }^{22}$.

En Perú, su Constitución, en el artículo 206, señala que toda reforma a la Constitución debe ser aprobada en referéndum. Sin embargo, puede omitirse el referéndum cuando el acuerdo del Parlamento se obtiene en dos legislaturas ordinarias sucesivas con una votación favorable, en ambos casos, superior a las dos terceras partes de los miembros del Parlamento.

En consecuencia, la diferencia entre el referéndum en Chile y en Perú pasa porque en el primero se trata de un poder de reacción del Ejecutivo frente a la Legislatura, al cual puede acudir el Presidente, en forma de plebiscito, en caso de desacuerdo con una reforma constitucional aprobada por el Congreso.

La Constitución de Colombia, por su parte, establece dos modalidades de referéndum constitucional. La primera está regulada en el artículo 377, que prescribe que los ciudadanos poseen facultad para solicitar que se sometan a referéndum las reformas constitucionales aprobadas por el Congreso Nacional, cuando se refieran a los derechos y garantías, a los procedimientos de participación popular y al Congreso. Este tipo de referéndum implica una facultad ciudadana que, para ser ejercida, requiere el concurso del cinco por ciento del registro electoral, y debe ser solicitada dentro de los seis meses siguientes a la expedición de haberse producido la reforma. La reforma se entenderá derogada por el sufragio negativo de la mayoría de los votantes, siempre que en la votación haya concurrido, al menos, la cuarta parte del registro electoral. Por tanto, la particularidad de este tipo de referéndum reside en que se trata de un referéndum derogatorio, por iniciativa ciudadana, respecto de una reforma aprobada por el Congreso Nacional. Una iniciativa que, de ser ejercida en el marco de los requisitos previstos, resulta ineludible.

En tanto, la segunda modalidad de referéndum se encuentra regulada en el artículo 378, en concordancia con el artículo 155, que disponen que el Congreso Nacional, a iniciativa del Gobierno o de los ciudadanos, en un porcentaje de, al menos, el cinco por ciento del registro electoral, y mediante ley que precisa la aprobación de la mayoría de los integrantes de ambas Cámaras, puede convocar al pueblo a que vote en referéndum un determinado proyecto de reforma a la

22 En la experiencia constitucional chilena referéndum y plebiscito, según NoGUEIRA ALCALÁ, son términos que pueden ser utilizados como sinónimos. Véase, Nogueira Alcalá (1993), p. 85. 
Constitución, cuyo texto el propio Congreso debe incluir en el articulado de ley de la convocatoria. Para que se considere aprobada una reforma constitucional por vía de referéndum, se exige el voto favorable de más de la mitad de los sufragantes, y que la participación de éstos supere la cuarta parte del total de ciudadanos que integren el registro electoral. En este caso, la decisión final sobre la convocatoria del referéndum queda en manos del Congreso.

La Constitución de Costa Rica, por su lado, en el artículo 195, número 8, en concordancia con el artículo 105, prescribe que las reformas constitucionales podrán someterse a referéndum después de ser aprobadas en una legislatura y antes de la siguiente, si así lo acuerdan los dos tercios de los congresistas.

Finalmente, la Constitución de Venezuela, a partir del artículo 341, que regula la enmienda, y el artículo 342, que regula la reforma parcial, exige que se convoque, en ambos casos, a referéndum. En el caso de las enmiendas, el referéndum se convocará luego de treinta días de la recepción formal de éstas por parte del Poder Electoral, y, en el caso de la reforma parcial, treinta días después de la aprobación de las modificaciones en sede legislativa.

Por tanto, en el caso de Colombia, su Constitución contempla dos modalidades de referéndum constitucional, el derogatorio de una reforma previamente aprobada por el Congreso (art. 377), y el aprobatorio (art. 378). Ambos referéndums, derogatorio y aprobatorio, pueden ser activados por iniciativa popular, posibilidad última que es compartida por Venezuela. Por el contrario, en Costa Rica, el referéndum se activa por petición de los dos tercios de la Asamblea Legislativa.

En definitiva, desde una perspectiva teórica constitucional, no se discute la comprensión del referéndum como un importante instrumento de democracia directa que viene a complementar el sistema representativo ${ }^{23}$.

\section{d) Previsión de Asamblea Constitucional y Asamblea Constituyente}

Entre los países estudiados, la previsión, ya sea de Asamblea Constitucional o de Asamblea Constituyente, dentro de sus Constituciones, es, cuando existe, una característica relevante en materia de procedimientos de reforma constitucional. La diferencia entre Asamblea Constitucional y Asamblea Constituyente pasa por el hecho de que en la segunda, al ser expresión del poder constituyente originario, su instalación supone la actuación de un poder facultado para

${ }^{23}$ La discusión así pone el acento en cómo el referéndum puede mejorar la calidad de la democracia. Al respecto véase,Tierney (2009), p. 7. 
sustituir la Constitución existente. En tanto, las Asambleas Constitucionales son expresión del poder constituyente derivado, y, en esa medida, están facultadas para reformar la Constitución, pero dentro del marco por ella previsto. En consecuencia, su actuación no implica la posibilidad de sustituir o cambiar totalmente la Constitución.

Así, la Constitución argentina, vigente desde 1853, si bien, ha sufrido a lo largo del tiempo varias reformas, entre las que destaca la última de 1994, contempla, en su artículo 30, tanto la modificación parcial como la total de la Constitución, cuya necesidad deberá ser declarada por las dos terceras partes de los miembros de la legislatura. Esta reforma constitucional solamente se puede llevar a cabo por una Convención convocada para el efecto. En consecuencia, en el caso argentino no estamos frente a una Asamblea constituyente, sino ante una Convención de carácter constitucional. Este procedimiento está inspirado en la Constitución de Estados Unidos, la cual señala en su artículo $\mathrm{V}$ los dos procedimientos para reformarla, uno de los cuales prevé que una Convención constituyente puede llevar a cabo los cambios constitucionales.

El artículo 376 de la Constitución colombiana señala que, mediante ley aprobada por mayoría de los integrantes de ambas Cámaras, el Congreso podrá disponer que el pueblo en votación popular decida si convoca una Asamblea Constituyente con la competencia, el período y la composición que la misma ley determine. Más adelante, señala que se entenderá que el pueblo convoca la Asamblea si así lo aprueba, al menos, una tercera parte de los integrantes del registro electoral. Después, el mencionado artículo determina que la Asamblea deberá ser elegida por el voto directo de los ciudadanos, en una elección que no podrá coincidir con otra. Finalmente, el artículo 376 afirma que, a partir de la elección, quedará en suspenso la facultad ordinaria del Congreso para reformar el Texto constitucional durante el tiempo determinado para que la Asamblea cumpla sus funciones. La Asamblea adoptará su propio reglamento. Por tanto, Asamblea Constituyente y Congreso funcionan simultáneamente ejerciendo sus competencias correspondientes.

Ahora bien, la Asamblea Constituyente es solo uno de los procedimientos que contempla la Constitución colombiana de 1991 para que se pueda proceder a su reforma. Además, si bien el pueblo colombiano decide por votación si se da o no la instalación de una Asamblea Constituyente, para la convocatoria de la votación debe mediar, en todo caso, una ley aprobada por la mayoría de los miembros de los dos Cámaras que componen el Congreso, lo cual hace que se califique a dicha Asamblea como un órgano constituyente constituido ad hoc o 
eventual ${ }^{24}$. Por ello, la denominación de Asamblea Constituyente no es precisa, debiendo ser catalogada como constitucional. En esa medida, la Asamblea no debe ser confundida con el ejercicio del poder constituyente originario, ya que desarrolla una tarea restringida, propia del poder constituyente constituido ${ }^{25}$.

Por el contrario, las Constituciones de Costa Rica, Venezuela, Ecuador y Bolivia prevén Asambleas Constituyentes dentro de sus Textos constitucionales. En la Constitución de Costa Rica de 1949 se aprobó, mediante la Ley No 4.123, de 31 de mayo de 1968, una reforma constitucional por la cual se prevé la instalación de una Asamblea Constituyente cuando se intente llevar adelante una reforma general de la Constitución. Así, el artículo 196 del Texto constitucional costarricense señala en la actualidad que la reforma general de aquél sólo podrá efectuarse por una Asamblea Constituyente convocada al efecto.

La ley que haga la convocatoria deberá ser aprobada por, al menos, las dos terceras partes de los miembros de la Asamblea Legislativa y no requiere sanción del Poder Ejecutivo. En consecuencia, la regulación constitucional del país centroamericano en materia de reforma total de la Constitución se mostró a finales de la década de los sesenta del siglo XX como una importante aportación al constitucionalismo de América Latina, en la medida en que, al considerar la revisión total como operación normalizada dentro del propio Texto constitucional, suponía una comprensión del poder constituyente precursora de la fase evolutiva en la que se encuentra el Estado constitucional en América Latina en nuestros días ${ }^{26}$.

La Constitución venezolana de 1999, en su artículo 347, afirma de modo explícito que el pueblo de Venezuela es el depositario del poder constituyente originario, en ejercicio del cual puede convocar una Asamblea Nacional Constituyente con la finalidad de transformar al Estado, crear un nuevo ordenamiento jurídico y redactar un nuevo texto constitucional. En consecuencia, en Venezuela, la Asamblea prevista en el artículo 347 de su Constitución tiene un carácter constituyente originario y plenos poderes.

A continuación, el artículo 348 de la Constitución de Venezuela afirma que la iniciativa de convocatoria a la Asamblea Nacional Constituyente podrán presentarla el Presidente de la República en Consejo de Ministros; la Asamblea Nacional, mediante acuerdo de los dos tercios de sus miembros; los Consejos Municipales

24 Zuluaga (2009), p. 324.

25 Ramírez Cleves (2005), p. 453.

26 HäBerLe (2003), pp. 136-137. 
en cabildos, mediante el voto de los dos tercios de los mismos; y el quince por ciento de los votantes inscritos en el registro electoral.

Por su parte, la Constitución ecuatoriana de 2008, en su artículo 444, sostiene que la Asamblea Constituyente sólo podrá convocarse por medio de consulta popular, la cual podrá ser pedida por el Presidente de la República, los dos tercios de los miembros de la Asamblea Nacional o el doce por ciento de los inscritos en el registro electoral. A continuación, se señala que la consulta deberá incluir la forma de elección de los representantes, así como las reglas del proceso electoral. Finalmente, para que la Constitución redactada por dicha Asamblea Constituyente entre en vigor, deberá contar con el respaldo popular de la mayoría absoluta de los votos válidos en un referéndum constituyente.

Por tanto, el artículo 444 de la Constitución ecuatoriana se puso a tono con las perspectivas doctrinales que observan la importancia legitimadora de la participación democrática directa en los cambios constitucionales y, por otro, se sumó a las aportaciones más recientes del constitucionalismo latinoamericano.

Por último, en la misma línea, el artículo 411 I de la Constitución boliviana prescribe que la reforma total de la Constitución, o aquella que afecte a sus bases fundamentales, a los derechos, deberes y garantías, o a la primacía y reforma de la Constitución, tendrá lugar a través de una Asamblea Constituyente originaria plenipotenciaria, activada por voluntad popular a través de referéndum. En este punto, coincide, en consecuencia, con la regulación constitucional venezolana y ecuatoriana.

Más adelante, el artículo 411 I de la Constitución de Bolivia señala que la convocatoria a referéndum se realizará por iniciativa ciudadana, con el respaldo de, al menos, el veinte por ciento del electorado, por mayoría absoluta de los miembros de la Asamblea Legislativa Plurinacional o por el Presidente de la República. Por tanto, coincide con los casos venezolano y ecuatoriano en que la iniciativa para convocar a Asamblea Constituyente se hace descansar en los ciudadanos, si bien varía el porcentaje requerido, en la Asamblea Legislativa y en el Presidente de la República, pero, adicionalmente, la Constitución de Venezuela reconoce también la iniciativa de los Consejos Municipales. Además, como característica relevante, debemos señalar que, mientras en Bolivia y Ecuador la Asamblea Constituyente se convoca previa consulta popular, en Venezuela no se exige consulta popular para la convocatoria, en la medida en que basta que la iniciativa se adopte por quienes tienen la facultad para ejercerla (art. 348).

Finalmente, el artículo 411 I de la Constitución de Bolivia dispone que la Asamblea Constituyente se autorregulará, debiendo aprobar el nuevo texto cons- 
titucional por las dos terceras partes de los presentes, y que la entrada en vigor de la reforma necesitará referéndum constitucional aprobatorio.

En consecuencia, a diferencia de Ecuador y Venezuela, el Texto constitucional boliviano no precisa de una aprobación de dos tercios de la mayoría de miembros de la Asamblea Constituyente, pues requiere solo dos terceras partes de los asistentes a la sesión. Por otro lado, al igual que en Ecuador, la regulación constitucional adoptada por la Asamblea Constituyente debe ser finalmente puesta a consideración del electorado y aprobada en referéndum por mayoría absoluta de votos, a diferencia de Venezuela, cuya Constitución no contempla la ratificación por medio de referéndum constituyente de la Constitución aprobada por la Asamblea Constituyente.

Por tanto, cuando hablamos de Argentina y Colombia, estamos, en la práctica, frente a casos de Asambleas o Convenciones Constitucionales, a pesar de que en Colombia su Constitución se refiere a Asamblea Constituyente, en tanto que, cuando nos referimos a Costa Rica, Venezuela, Ecuador y Bolivia, nos encontramos frente a Asambleas Constituyentes plenipotenciarias, expresión del poder constituyente originario. Dicha distinción, al menos en los casos de Venezuela, Ecuador y Bolivia, tiene como asidero el planteamiento del nuevo constitucionalismo latinoamericano, que promueve la tesis del origen radicalmente democrático de las Constituciones, el cual supone la necesidad de acudir al pueblo cuando de reformas constitucionales se trate, fortaleciendo, así, la identidad entre soberanía popular y Constitución ${ }^{27}$.

En efecto, la previsión de Asamblea Constituyente dentro de algunas Constituciones latinoamericanas obedece a la finalidad de legitimar democráticamente su reforma profunda, de ahí que la tendencia sea que dichas reformas esenciales sean tramitadas por órganos extraordinarios y no por los órganos ordinarios ${ }^{28}$.

En consecuencia, las Asambleas Constituyentes contempladas en las Constituciones de Venezuela, Ecuador y Bolivia promueven la actuación directa de la ciudadanía en la instalación de dichas Asambleas, que son convocadas por consulta popular, así como por la introducción del referéndum ratificatorio del texto aprobado por las Asambleas Constituyentes en Ecuador y Bolivia ${ }^{29}$.

27 Viciano Pastor y Martínez Dalmau (2010), p. 18.

28 Colón Ríos (2015), p. 3.

29 Dichos procedimientos operan como vehículos de transformación democrática de los procesos de cambio constitucional. Véase, Pisarello (2012), p. 18. 


\section{A MOdo DE BALANCE}

En lo que se refiere al apoyo requerido para las iniciativas parlamentarias de enmienda y reforma, la Constitución ecuatoriana se encuentra en el grupo de aquellas que exige un mayor porcentaje de apoyo. Con respecto a las mayorías parlamentarias exigidas para la aprobación de la reforma constitucional, lo más destacable es que, tanto en el procedimiento de enmienda, como en el de reforma, se requiere la mayoría de dos tercios de los miembros de la Asamblea Nacional, que es la más elevada entre las que se contemplan en el Derecho comparado. Ello da cuenta de una fuerte tendencia hacia la rigidez de la Constitución.

En cuanto al referéndum, la Constitución de Ecuador se inscribe en el marco de aquellas que lo contemplan en el marco del procedimiento de reforma de la Constitución, tales como Bolivia, Colombia, Costa Rica, Perú y Venezuela . En todo caso, destacan en la Constitución de Ecuador dos características, como son, en primer lugar, que el referéndum no es necesario cuando la enmienda sigue tramitación legislativa en la Asamblea Nacional, y, en segundo lugar, que el referéndum es exigido aun cuando se convoque a la Asamblea Constituyente. El primer elemento hace que deba reevaluarse la posición del referéndum en el procedimiento de enmienda. En efecto, la interpretación que se viene haciendo del artículo 441 de la Constitución permite, sobre todo cuando la iniciativa provenga del Presidente y las fuerzas que lo apoyen en la Asamblea Nacional dispongan de la mayoría de dos terceras partes en este órgano, sortear el referéndum, dado que, en tales casos, la enmienda puede ser aprobada en la propia Asamblea Nacional mediante dicha mayoría ${ }^{30}$.

De otro lado, la Constitución de Ecuador se inscribe también en el grupo de aquellas que regulan la convocatoria de una Asamblea Constituyente como procedimiento para la reforma de la Constitución, como es el caso de Colombia, Costa Rica, Venezuela y Bolivia, aun cuando, como hemos visto, la doctrina mantenga discrepancias acerca del carácter verdaderamente constituyente de la

30 Como ejemplo de ello se puede citar el proceso de reformas constitucionales de 2015, en la que se eliminó la prohibición de la reelección por más de una ocasión del Presidente de la República, dando paso en consecuencia a la reelección indefinida. Véase al respecto, Corte Constitucional del Ecuador, Dictamen 001-14-DRC, Caso No 0001-14-DRC, de 31 de octubre de 2014. Sin embargo, se debe señalar que la prohibición de reelección por más de una ocasión para toda autoridad de elección popular, incluido el Presidente de la República, fue reinstaurada a partir del referéndum constitucional de 4 de febrero de 2018. De ahí que en Ecuador vuelve a estar prohibida la reelección por más de una ocasión consecutiva o no del Presidente de la República, retornando así a la voluntad primigenia del constituyente contemplada en los artículos 114 y 144 de la Constitución de 2008. 
Asamblea contemplada en la primera Constitución citada. La previsión de la Asamblea Constituyente se da para aquellos casos en que la reforma afecte a los elementos cuya importancia la Constitución ha querido destacar especialmente, como es el caso de los derechos y el procedimiento de reforma constitucional, o bien para la revisión total de la Constitución. Es decir, la Asamblea Constituyente no es elemento necesario para la reforma, sino que se contempla solamente en los casos en que la reforma tenga especial gravedad, o se vaya a reformar de modo total la Constitución, lo cual es la tendencia normal en el constitucionalismo de América Latina de hoy en día.

En suma, desde la comprensión de un constitucionalismo fuerte ${ }^{31}$, que se caracteriza por la existencia de cláusulas de intangibilidad, así como por la exigencia de mayorías calificadas en la tramitación de reformas constitucionales, diríamos que de los países analizados se desprenderían tres niveles de rigidez. Así, entre las Constituciones más rígidas tendríamos a Bolivia, Brasil, Chile, Perú y Venezuela, seguidas por los Textos de Colombia y Costa Rica, y, finalmente, ubicamos como los Textos menos rígidos el de Argentina y el de México. Ecuador se encuadraría, a estos efectos, en el grupo de los países con Constituciones más rígidas.

Si como habíamos dicho en el primer apartado del manuscrito, hoy en día la inmensa mayoría de los Estados constitucionales contemplan, por un lado, Constituciones rígidas y, por otro, Cortes y Tribunales Constitucionales, la relación entre ambos elementos encuentran un punto de intersección en la posibilidad del control constitucional de las reformas a la Constitución por parte de aquellos órganos ${ }^{32}$. Control que, sin embargo, no deja de ser polémico, en la medida en que el objeto de control es, finalmente, el poder constituyente, lo cual acrecienta la objeción contramayoritaria respecto de los tribunales ${ }^{33}$. En esa medida se suele afirmar que, para matizar la tensión democrática el control debería ser, principalmente, de corte formal y procedimental y, cuando el pueblo

31 BAYÓN (2003), p. 216.

$32 \mathrm{Al}$ respecto puede consultarse el trabajo de RAGONE, Sabrina (2012): El control judicial de la reforma constitucional. Aspectos teóricos y comparativos (México, Editorial Porrúa).

33 La teoría constitucional de corte liberal democrático, como es bien sabido, sugiere que los mejor ubicados institucionalmente para llevar a cabo el control de constitucionalidad de enmiendas inconstitucionales son los jueces, en el sentido de asimilar dicha tarea a la revisión judicial de la ley. No obstante, la discusión no está saldada, en la medida en que las teorías democráticas participativas cuestionan la tesis del por qué los jueces, necesariamente, deben ser los autorizados para fijar los límites de lo que es constitucional o no en un proceso de enmienda a la Constitución. Albert (2009), pp. 9-10. 
no haya participado en el proceso por medio de referéndum ${ }^{34}$. No obstante, más allá de la objeción señalada de los países analizados contemplan de modo explícito el control de las reformas a la Constitución en el caso de Chile (art. 93.3), Colombia (art. 241.1), Ecuador (art. 443) y Bolivia (art. 202.10). En tanto que, en el caso de Argentina y México, ante la inexistencia de una disposición constitucional que les otorgue dicha facultad, sus Cortes Supremas han asumido dicha facultad, actuación que, ha sido seguida también por parte del Tribunal Constitucional del Perú. Por su lado, la Constitución brasileña de 1988 no le otorga con carácter general la competencia de llevar a cabo el control de la reforma al Texto constitucional al Supremo Tribunal Federal. Sin embargo, dicho Tribunal ha sostenido la necesidad de llevar a cabo el control cuando las reformas atenten contra lo dispuesto por las cláusulas de intangibilidad 35 . Por su lado, la Sala especializada de lo Constitucional de la Corte Suprema de Costa Rica, a partir del artículo 10 de la Constitución, defiende la potestad de la Sala para declarar la inconstitucionalidad de toda norma indistintamente de su naturaleza. Venezuela, finalmente, no completa ningún tipo de control constitucional respecto del poder de reforma constitucional.

De los países latinoamericanos mencionados, la Corte Constitucional de Colombia se muestra como un caso paradigmático del control constitucional de la reforma constitucional, por medio de su doctrina de la sustitución de la Constitución, la cual le permitió a la Corte revisar el contenido de una reforma y no solo vigilar por el respeto de los aspectos procedimentales. Además la doctrina en cuestión alude al hecho de que el poder de reforma al tratarse de un poder que su ejercicio se enmarca dentro de lo dispuesto por la Constitución, no tiene facultad para cambiar el núcleo esencial de esta. Distinción que, en definitiva, supone la diferenciación entre poder constituyente originario y derivado. La doctrina constitucional en cuestión ha sido desarrollada en algunas sentencias de la Corte Colombiana que iniciando en el año 2003, con la Sentencia C-551, en el 2010 con motivo de la Sentencia C-141, tuvo un importantísimo aporte para el sistema democrático cuando la Corte señaló que una reforma que introduce la posibilidad de la segunda reelección del entonces Presidente Álvaro Uribe, suponía una sustitución de la Constitución. Toda vez

34 Ferreres Comella (2012), p. 219.

35 Como prescribe el artículo 60, número 4, de la Constitución, que determina que no será objeto de deliberación una propuesta tendiente a abolir la forma federal de Estado, el voto directo, universal, directo, periódico, la separación de poderes y los derechos fundamentales. 
que la reforma modificaba el equilibrio entre frenos y contrapesos, así como la alternancia en el ejercicio del poder y la igualdad entre los candidatos que postulen para la presidencia de la República, todos ellos principios identitarios del Texto constitucional de $1991^{36}$.

\section{CONCLUSIONES}

Como ha sido visto, la Constitución ecuatoriana suscribe los avances más actuales de los textos constitucionales latinoamericanos, en la medida en que apuesta por una Constitución normativa que abraza distintos grados de rigidez, dependiendo de los temas que se vayan a modificar. De ahí, precisamente, los procedimientos diferenciados de enmienda constitucional, reforma parcial y Asamblea Constituyente. Asimismo, se establecen distintos mecanismos de participación popular directa, que van desde la iniciativa ciudadana para la reforma hasta la aprobación de los cambios por medio de referéndum.

En efecto, la introducción de mecanismos de democracia directa en el trámite de las reformas constitucionales proporcionan un fuerte ascendiente de legitimidad al procedimiento de reforma. En esa medida se muestra difícil el comprender el procedimiento de enmienda, mecanismo que comporta un menor grado de rigidez, cuando aquélla tiene su origen en los miembros de la Asamblea Nacional, toda vez que en este caso no se precisa de referéndum para aprobar los cambios llevados a cabo por parte del legislativo.

Mención especial nos merece la regulación de la Asamblea Constituyente dentro del articulado constitucional, en la medida en que, por un lado, disminuye la idea de extraordinariedad el cambio de alguno de los elementos que conforman la decisión política fundamental, toda vez que dicha Asamblea viene debidamente regulada por la propia Constitución que va a sustituir. En tanto que, de otro lado, al consistir la Asamblea Constituyente en la vía más rígida, protege de mejor manera la progresividad de los derechos, las garantías constitucionales, así como el cambio del procedimiento mismo de reforma a la Constitución. Aspectos que están prohibidos de ser modificados por los trámites de enmienda y reforma parcial. En este sentido, es fundamental la actuación de la Corte Constitucional de Ecuador para hacer que se observen los límites impuestos por el constituyente tanto a la enmienda como a la reforma parcial.

$36 \mathrm{Al}$ respecto véase Bernal Pulido, Carlos (2013), pp. 341-346. 


\section{BibliografÍA CitAdA}

AlberT, Richard (2009): "Nonsconstitutional Amendments", en Canadian Journal of Law and Jurisprudence (No 22), pp. 9-10 [fecha de consulta: 12 de abril de 2018] [Disponible en: http://lawdigitalcommons.bc.edu/cgi/viewcontent. cgi?article $=1510 \&$ context $=1 \mathrm{sfp}]$.

BAYÓN, Juan Carlos (2003): "Derechos, Democracia y Constitución”, en Neoconstitucionalismo(s), Ed. Miguel Carbonel (Madrid, Editorial Trotta).

BAYÓN, Juan Carlos (2010): "Democracia y derechos: problemas de fundamentación del constitucionalismo", en El canon neoconstitucional, Eds. Miguel Carbonell y Leonardo García Jaramillo (Bogotá, Universidad Externado de Colombia).

Benavides Ordóñez, Jorge (2016): "Neoconstitucionalismo, Nuevo Constitucionalismo Latinoamericano y Procesos Constituyentes en la Región Andina”, en Revista Ius Humani. Revista de Derecho (Vol. 5), p. 184 [fecha de consulta: 13 de abril de 2018] [Disponible en: http://www.iushumani.org/revistadederecho/ index.php/iushumani/article/view/99/85].

Bernal Pulido, Carlos (2013): "Unconstitutional constitutional amendments in the case study of Colombia: An analysis of the justification and meaning of the constitutional replacemant doctrine", en International Journal of Constitutional Law, (Vol. 2), pp. 341-346 [fecha de consulta: 12 de abril de 2018]. [Disponible en: https://academic.oup.com/icon/article/11/2/339/753642].

BoCKENFORDE, Ernst Wolfang (2000): "El poder constituyente del pueblo. Un concepto límite del Derecho constitucional", en Estudios sobre el Estado de Derecho y la democracia, (Madrid, Trotta).

Colón Ríos, Jhoel (2015): “Apuntes sobre Legitimidad Democrática y Asambleas Constituyentes", en Revista Argentina de Teoría Jurídica, (Vol. 16), p. 3 [fecha de consulta: 14 de diciembre de 2016] [Disponible en: http://www.utdt.edu/ ver_contenido.php?id_contenido=111698id_item_menu=5858].

De Vega, Pedro (1985): La reforma constitucional y la problemática del poder constituyente (Madrid, Tecnos).

Ferreres Comella, Víctor (2012): Justicia constitucional y democracia (Madrid, Centro de Estudios Políticos y Constitucionales).

Gargarela, Roberto (2011): "Pensando sobre la reforma constitucional en América Latina”, en El derecho en América Latina: un mapa para el pensamiento jurídico en el siglo XXI, coord. César Rodríguez Garavito (Buenos Aires, Editorial Siglo XXI). 
Garrorena, Ángel (2014): Derecho Constitucional. Teoría de la Constitución y sistema de fuentes (Madrid, Centro de Estudios Políticos y Constitucionales).

HäBerle, Peter (2003): El Estado Constitucional (Lima, Pontificia Universidad Católica del Perú).

Hesse, Konrad (1992): Escritos de Derecho Constitucional (Madrid, Centro de Estudios Constitucionales).

Nogueira Alcalá, Humberto (1993): Regímenes politicos contemporáneos, (Santiago, Editorial Jurídica Chile).

Nogueira Alcalá, Humberto (2009): "Poder Constituyente y Reforma Constitucional: enfoque teórico y concreción práctica al caso chileno", en La Reforma Constitucional. Sus implicaciones jurídicas y politicas en contexto comparado, coord. Pedro Torres y Michael NúŃEz (México, Editorial Porrúa).

Pérez Royo, Javier (2007): Curso de Derecho Constitucional (Madrid, Marcial Pons).

PisArello, Gerardo (2012): Procesos constituyentes. Caminos para la ruptura democrática (Madrid, Editorial Trotta).

Ragone, Sabrina (2012): El control judicial de la reforma constitucional. Aspectos teóricos y comparativos (México, Editorial Porrúa).

Ramírez Cleves, Gonzalo (2005): Limites de la Reforma Constitucional en Colombia. El concepto de Constitución como fundamento de la restricción (Bogotá, Universidad Externado de Colombia).

Schmiтt, Carl (2012): Teoría de la Constitución (Madrid, Editorial Alianza).

TIERney, Stephen (2009): Constitutional Referendums: A Theorical Enquiry, p. 7 [fecha de consulta: 13 de abril de 2018] [Disponible en: https://www.upf. edu/dcpis/_pdf/2009-2010/forum/Tierney_paper.pdf].

UprimnY, Rodrigo (2011): "Las transformaciones constitucionales recientes en América Latina: tendencias y desafíos", en El derecho en América Latina: un mapa para el pensamiento jurídico en el siglo XXI, coord. César RodRíGUEZ Garavito (Buenos Aires, Editorial Siglo XXI).

Viciano Pastor, Roberto y Martínez Dalmau, Rubén (2010): "Aspectos generales del nuevo constitucionalismo latinoamericano", en El nuevo constitucionalismo de America Latina. Memorias del encuentro internacional El nuevo constitucionalimo: Desafios y Retos para el siglo XXI (Quito, Corte Constitucional Ecuador). Zuluaga, Oscar (2009): "Reforma o supremacía. Una aproximación a la Constitución con especial referencia a Colombia" en La Reforma Constitucional. Sus implicaciones jurídicas y politicas en contexto comparado, coord. Pedro TORRES y Michael NúNEzz (México, Editorial Porrúa). 
NORMAS JURÍDICAS CITADAS

Constitución de Argentina.

Constitución de Bolivia.

Constitución de Brasil.

Constitución de Chile.

Constitución de Colombia.

Constitución de Costa Rica.

Constitución de Ecuador.

Constitución de México.

Constitución de Perú.

Constitución de Venezuela.

$$
\text { JURISPRUDENCIA }
$$

Corte Constitucional de Ecuador, Dictamen 001-14-DRC, Caso No 0001-14DRC, de 31 de octubre de 2014. 